\title{
MOBILIZAÇÃO DA OPINIÃO PÚBLICA E O ESCÂNDALO DOS DIÁRIOS SECRETOS NA ASSEMBLÉIA LEGISLATIVA DO PARANÁ
}

Anne Carolina Festucci, Patricia Guilhem De Salles Carvalho, Paula Maia Wunder Andreola 
MOBILIZAÇÃO DA OPINIÃO PÚBLICA E O ESCÂNDALO DOS DIÁRIOS SECRETOS NA ASSEMBLÉIA LEGISLATIVA DO PARANÁ

Resumo: $\mathrm{O}$ artigo propõe analisar os conceitos relacionados à mobilização da opinião pública, apresentados por diferentes autores, como ferramenta de estudo para entender qual foi o verdadeiro impacto da série "Diários Secretos": uma série de reportagens divulgada pela Rede Paranaense de Comunicação (RPCTV) e o Jornal Gazeta do Povo, em que mostra tanto as movimentações de funcionários, como os escândalos e roubos ocorridos na Assembleia Legislativa do Paraná.

Palavras chave: Cidadania; Opinião Pública; Diários Secretos

MOVILIZACIÓN DE LA OPINIÓN PÚBLICA Y EL ESCÁNDALO DE LOS DIARIOS SECRETOS EN LA ASSEMBLÉIA LEGISLATIVA DO PARANÁ

Resumen: El artículo tiene como objetivo analizar los conceptos relacionados con la movilización de la opinión pública, presentado por diferentes autores, como una herramienta de estudio para comprender cuál es el impacto real de la serie "Diários Secretos": una serie de informes publicados por Rede Paranaense de Comunicação (RPCTV) y el periódico Gazeta do Povo, que muestra tanto el movimiento de los empleados, como los escándalos y robos que ocurren en la Assembléia Legislativa de Paraná.

Palabras clave: Ciudadanía; Opinión Pública; Diários Secretos

MOBILIZATION OF PUBLIC OPINION AND THE SCANDAL OF SECRET DIARIES IN THE LEGISLATURE OF PARANÁ

Abstract: The article proposes analyze the concepts related to the mobilization of public opinion, presented by different authors, as a study tool to understand what was the real impact of the tv serie "Diários Secretos": a serie of reports published by Rede Paranaense de Comunicação (RPCTV) and Jornal Gazeta do Povo, which shows both the movement of employees, as the scandals and robberies that occurred in the Assembléia Legislativa do Paraná.

Keywords: Citizenship; Public Opinion; Secret Diaries 


\section{INTRODUÇÃO}

Em 16 de Março de 2010, a Rede Paranaense de Comunicação (RPCTV) e o Jornal Gazeta do Povo deram início à série "Diários Secretos". Essa série de reportagens apresentou todas as movimentações de funcionários da Assembléia Legislativa do Paraná, mostrando escândalos e roubos ocorridos na Assembléia. Até o final da série, em 24 de Abril de 2010, nomes, prisões, recadastramentos, protestos, entre outros acontecimentos foram revelados.

A investigação sobre os diários começou quase dois anos antes da divulgação, tendo como jornalistas responsáveis Karlos Kohlbach, Katia Brembatti, James Alberti e Gabriel Tabatchek. A análise foi feita em mais de 700 diários oficiais editados entre 1999 e 31 de Março de 2009. "A investigação revelou a existência de 2.178 atos secretos do Legislativo entre janeiro de 2006 e março de 2009. Todos publicados em diários oficiais avulsos, que serviam para ocultar nomeações, demissões e pagamentos irregulares". (GAZETA DO POVO, 2010)

As reportagens transmitidas pela RPCTV mostraram a existência de atos secretos na Assembleia, indícios de desvio de dinheiro público e uso de funcionários fantasmas. No início da série, a Assembleia Legislativa não prestou nenhuma explicação sobre as denúncias, mas de acordo com a gravidade das informações, alguns nomes foram revelados, como os de Abib Miguel, ex-diretor geral da Alep e José Nassif. A partir daí, houve uma pressão da opinião pública e providências foram tomadas. Nelson Justus, presidente na época da Assembleia, que inicialmente negou as irregularidades, abriu uma sindicância interna e anunciou o recadastramento de todos os funcionários da Casa.

Com as demais acusações, os fatos foram se desenrolando e entre eles é possível destacar algumas informações mais relevantes. Na semana do dia 19/03/2010, Abib Miguel e José Nassif pedem afastamento do cargo e estudantes protestam em frente à Casa. Duas semanas após, o Ministério Público abre inquérito para investigar Nelson Justus e sindicalistas invadem assembleia pedindo afastamento da mesa diretora. No dia 20/04, a Assembleia Legislativa exonera 237 funcionários comissionados, 22 deles apontados em irregularidade na série Diários Secretos.

Após dois anos da divulgação dos escândalos e das denúncias mostradas pela série Diários Secretos, segundo reportagem do site da Gazeta do Povo, em 16/03/2012, nenhum acusado do esquema de desvio de recursos na Assembleia foi julgado pela Justiça. Apesar de os julgamentos não terem ocorrido, o 
MOBILIZAÇÃO DA OPINIÃO PÚBLICA

Ministério Público conseguiu bloquear os bens de dos responsáveis pela gestão de recursos do Legislativo, em caráter de liminar. Os deputados Nelson Justus, ex-presidente da Casa, Alexandre Curi, ex primeiro secretário e Nereu Moura, além do ex-deputado e atual conselheiro do Tribunal de Contas Hermas Brandão estão com os bens indisponíveis, pelo fato de responderem ações por improbidade administrativa, já que o MP entendeu que tiveram responsabilidade pelas nomeações de fantasmas. A reportagem também chama atenção para a diminuição dos gastos na Assembleia devido à demissão de funcionários fantasmas e corte de pagamentos indevidos na remuneração dos servidores da Casa. "...o saldo - ao menos financeiro - é de uma economia média de R\$ 4,5 milhões todo o mês na folha de pessoal."

Como é um tema importante, que une política, opinião pública e veículos de comunicação, o objetivo do artigo em questão é relacionar o caso com os conceitos de opinião pública, sua formação e o papel da imprensa e dos institutos de sondagem na construção do acontecimento político, relacionando assim com o conceito de cidadania. Sendo assim, a metodologia utilizada é site da Gazeta do Povo, pesquisa bibliográfica, analisando autores como Patrick Champagne, Blumer, Habermas, Gabriel Cohn, Landowski, Tarde, entre outros.

\section{MOBILIZAÇÃO DA OPINIÃO PÚBLICA E SEUS CONCEITOS}

Para que se compreenda com rigor científico a forma e o conteúdo das interações entre opinião pública e mídia é necessário que se identifique alguns elementos e conceitos que acompanham essa relação. Dessa forma, é preciso analisar inicialmente o que se entende por massa, público e enfim opinião pública.

O conceito de massa, segundo Blumer (apud COHN, 1978, p.177) indica um grupo coletivo, espontâneo, de qualquer categoria social. "Composta por in-

divíduos anônimos, [...] existe pouca interação ou troca de experiência entre os membros da massa." Como possuem pouca interação, encontram-se fisicamente separados, não sendo capazes de agir de forma integrada.

Pode-se analisar a massa pela sua caracterização na sociedade e pela sua natureza de comportamento diante de fatos e acontecimentos. Seu objeto de interesse é tudo aquilo que atrai a atenção de pessoas para além de suas culturas e esferas de vida. Perante esses assuntos agem separadamente, enquanto indivíduos. A forma como recebem essas mensagens é através de veículos de comunicação de massa que transmitem informações nas suas determinadas programações. 
Ao receberem informações dos veículos de massa, acabam se caracterizando por grupo homogêneo em termos de comportamento massivo, já que atuam em resposta aos impulsos que lhes foram despertados pelo objeto de interesse. Assim, conforme o autor (1978, p. 179), "a resposta é dada pela busca de cada indivíduo que procura responder às suas próprias necessidades".

Para público, entende-se um agrupamento elementar coletivo e espontâneo em que é possível notar uma discussão. Normalmente esse público possui interesses comuns e se forma diante de determinada situação. O público, diferentemente da massa, consegue expressar uma opinião diante das informações que recebem, podendo dar um feedback imediato. E, ao contrário da multidão, não predomina o rumor e o estímulo grandioso. Sendo assim, o público age no intuito de alcançar uma decisão coletiva ou desenvolver uma opinião coletiva.

a peculiaridade do público reside no desacordo e na discussão quanto ao que se deve fazer. Interage na base de interpretação, entra em disputa e caracteriza-se por relações de conflito. Ao mesmo tempo, é provável que no interior de um público os indivíduos intensifiquem sua autoconsciência e fortaleçam suas capacidades críticas. [...] as argumentações são complexas, criticadas e enfrentadas por contra-argumentações (COHN, 1978, p. 183).

No caso estudado, público tem mais ligação com a definição de Tarde (1992), em que a palavra "público" é entendida como uma coletividade puramente espiritual, como uma disseminação de indivíduos fisicamente separados e cuja coesão é inteiramente mental.

Hoje em dia a aproximação dos corpos não é condição necessária para o contágio de uma opinião. Os homens que se sugestionam mutuamente, que transmitem uns aos outros a sugestão vinda de cima, não se tocam, não se vêem nem se ouvem, estão sentados, cada um em sua casa, lendo o mesmo jornal e dispersos num vasto território.

O vínculo que existe entre eles é a simultaneidade de sua convicção, a consciência que cada um deles possui de que essa idéia é partilhada no mesmo momento por um grande número de outros homens. Basta que ele saiba disso, mesmo sem ver esses homens, para que seja influenciado por estes tomados em massa, e não apenas pelo jornalista, inspirador comum, ele próprio invisível, desconhecido e, por isso mesmo, ainda mais fascinante.

Para o autor, é preciso analisar o que é sensação de atualidade, pois atua- 
lidade não é apenas o que acaba de acontecer, mas sim tudo que inspira atualmente um interesse geral, mesmo que se trate de um fato antigo, o que se pode ver nos relatos diários dos escândalos relatados pelos jornais.

O que os veículos em questão fizeram remete o que Tarde (1992) afirma a seguir, já que diariamente publicava matérias noticiando mais capítulos dos escândalos, dando essa continuidade ao fato:

Ora, a influência que o publicista exerce sobre seu público, embora muito menos intensa num instante dado, é bem mais poderosa, por sua continuidade, que pelo impulso breve e passageiro transmitido à multidão por seu condutor; além disso, ele é secundária, jamais combatida, pela influência bem menor que os membros de um mesmo público exercem uns sobre os outros, graças à consciência da identidade simultânea de suas idéias e tendências, de suas convicções ou de suas paixões, cotidianamente atiçadas pelo mesmo fole de forja (TARDE, 1992, p.40).

Segundo o autor, o leitor de um jornal dispõe bem mais de sua liberdade de espírito do que o indivíduo perdido e arrastado numa multidão. "Ele pode refletir em silêncio sobre o que lê e apesar de sua passividade habitual, poderá mudar de jornal, até encontrar o que lhe convém ou que ele julga melhor convir" (TARDE, 1992, p.41). Ao mesmo tempo em que o jornalista procura agradá-lo e retê-lo.

O autor acredita que o público age por eles e impõe-se aos homens de Estado que se tornam seus executores. Isso é o que se chama poder da opinião. “É verdade que ela atesta, sobretudo a de seus condutores, que a puseram em movimento, mas uma vez suscitada, essa opinião os arrasta por caminhos que não previram." (TARDE, 1992, p.66)

\subsection{Opinião pública e sondagens}

Quando se fala em opinião pública, nota-se que tal conceito não é facilmente apreensível. Envolve um conjunto de abstrações que servem para compor a definição. Além disso, por ser um conceito que está inserido na dinâmica política, ele ganha importância estratégica nas disputas pelos instrumentos e posições de poder, os quais servirão para determinar o teor das relações do mesmo.

Hebert Blumer (apud COHN, 1978), comenta que opinião pública deve ser encarada como um produto coletivo, diferente da opinião do público, não consti- 
tuindo uma opinião unânime e nem sempre representando a opinião da maioria. Conforme o autor (1978, p. 184), "pode-se considerá-la como sendo talvez uma opinião combinada, formada por diversas opiniões sustentadas pelo público".

O conceito de opinião pública ainda é discutido por diversos autores, tendo os que a consideram "a rainha do mundo" (PASCAL apud VIÁ,1983, p.07) e outros que tentam dar sua devida importância perante a sociedade.

A concordância do tema gira em torno do conceito de que opinião pública é um fenômeno social, é a manifestação de atitudes coletivas, que implica na existência de outras opiniões distintas. Segundo Viá (1983, p. 08) "para que exista uma opinião pública, necessita-se de pronunciamento unânime em uma mesma direção ou da maior parte dos seus membros de um grupo social”. Dependendo da classe social, das crenças e ideologias, a opinião pública irá se formar de uma maneira diferenciada.

A opinião pública, para Landowski, assume vários níveis sintáxicos, já que a próprio conceito de opinião pública carrega uma grande polissemia, já que se trata de um estudo na área da semiótica.

No primeiro caso, como destinador, seguir a opinião pública está ligado a se passar um discurso de pura legalidade jurídica a um discurso social que tem como objetivo justificar a oportunidade das decisões políticas tomadas no dia a dia. Enquanto que no segundo caso, como um anti-destinador, desafiar a opinião pública quer dizer que a classe política não querendo ou não devendo fazer o que a opinião pública quer, entra em combate com a opinião pública, travado pela "boa causa" de reconduzir essa mesma opinião pública na razão.

Já no terceiro caso, não destinador, quando a classe política engana a opinião pública ela se aproveita que a opinião não tem informação suficiente:

Duas formas narrativas devem ser distinguidas, segundo estado de desconhecimento em que se encontre a "opinião pública" seja simplesmente mantido pela não-intervenção das instâncias competentes - as quais se limitam, então, a deixar crer sua interlocutora em quimeras - ou resulte de um fazer crer deliberadamente enganador. No primeiro caso, estamos diante da demagogia, no segundo das formas ditas de manipulação da opinião (LANDOWSKI, 1992, p. 37).

Por fim, quando a classe política afronta a opinião pública, o autor quer dizer que se têm dois sujeitos que se medem no plano pragmático enquanto forças contrárias, ou seja, oposição essa que só pode finalizar na neutralização 
do poder fazer de uma das duas partes, "a prova, de qualificante que era antes (epistemê versus doxa), torna-se decisiva: o poder do Poder entra em conflito com o poder da Opinião." (idem, p.39)

Pierre Bourdieu (apud CHAMPAGNE, 1986, p.252) já dizia que "as pesquisas de opinião postulavam que todo mundo tem uma opinião sobre tudo, que todas as opiniões são equivalentes e têm a mesma força social".

Para os institutos de pesquisa, diz Patrick Champagne (1986, p 113), a opinião pública é, basicamente, a união de opiniões privadas que se tornam públicas. Não significa que a opinião se revela em público. Desta forma, os institutos de sondagem acabam coletando apenas um número $X$ de opiniões de indivíduos, que vão representar estatisticamente a população. O resultado obtido é dito "opinião pública" pelo simples fato de serem divulgados publicamente. Os profissionais das sondagens entendem que a opinião pública existe por si mesma e deve ser avaliada da forma mais precisa possível.

Deve-se então, de um ponto de vista mais técnico, avaliar se as pesquisas possibilitam apreender as opiniões reais sobre determinado problema, distinguindo as diversas formas que tais opiniões podem assumir: opiniões privadas já constituídas, opiniões individuais que só existem em estado potencial, opiniões coletivamente elaboradas e manifestadas publicamente e ainda, o grau de implicação dos indivíduos na questão levantada.

Perante os meios de comunicação, alguns líderes e partidos criam estereótipos sobre os candidatos e alteram ou induzem opiniões. Isso forma uma fantasia na mente das pessoas e faz com que elas mudem suas opiniões individuais e sejam levadas a crer naquilo que está sendo divulgado pela mídia.

Patrick Champagne (1986, p.251) defende que "na política, as aparências dão sempre razão às aparências já que conseguir levar a acreditar contribui para que algo exista". A notoriedade de um político e a boa opinião que a população pode ter a seu respeito está sendo redefinidas por publicitários e por especialistas do marketing.

O que, atualmente, nos parece "natural" - por exemplo, a maneira como os políticos fazem suas intervenções na televisão - trata-se de um "natural", na realidade, fabricado pelo e para o jogo político tal como se exprime nos meios modernos de comunicação: sabemos que os políticos preparam cuidadosamente seus "improvisos" televisionados e que essa verdadeira performance de ator exigida, atualmente, aos políticos diante das câmeras de televisão só, há bem pouco tempo, faz parte do "métier do político (CHAMPAGNE, 1986, p. 118). 
A formação de atitude e opinião pública é citada por Daniel Katz (apud COHN, 1978, p. 372) como conceitos que se relacionam. O primeiro, atitude, é "a organização específica de sentimentos e crenças, conforme a qual uma dada pessoa avalia positiva ou negativamente um objeto", o segundo, opinião pública, refere-se "a mobilização e canalização de respostas individuais no sentido de afetarem a tomada de decisão em termos grupais ou nacionais."

O fato de a mídia colocar um assunto para que o público torne-o como foco de atenção é o estágio inicial para a formação da opinião pública. Durante campanhas políticas a discussão sobre opinião pública gira em torno de quantos são a favor, quantos são contra e quantos estão indecisos.

Para Katz (1956), as pessoas mudam suas atitudes a fim de assegurar a aceitação em um grupo e para alcançar posições de liderança. Elas podem adotar atitudes ainda para promover seu próprio autointeresse, utilizando o caráter instrumental de atitudes para atingir suas metas.

Lazarsfeld (apud Wolf, 2002, p. 51) comenta que os efeitos provocados pelos meios de comunicação de massa dependem das forças sociais que predominam num determinado período. Portanto, o tema "Diários Secretos", é relacionado com os autores acima em relação aos processos de formação de opinião em uma sociedade e os motivos com que se formam as atitudes políticas no decorrer de uma campanha eleitoral.

Através da descoberta dos líderes de opinião e do fluxo de comunicação é possível observar que existem indivíduos muito envolvidos e interessados num processo, que representam parte da opinião pública e procuram influenciar o resto do eleitorado, que responde ao estímulo desses líderes. Conforme observa Champagne (1986, p.71) os jornalistas expressam sua opinião e julgam ser também a opinião de seus leitores. Esta opinião pré-ajustada ao público - lida pelos leitores - facilmente se tornam a opinião dos leitores e consequentemente é percebida como opinião pública.

Além de servir para difundir idéias políticas, a mídia aparece como aliado de determinadas organizações, que se aproveitam do momento em questão para divulgar pesquisas, escândalos e fazer merchandising. Essas divulgações podem, ou não, afetar a opinião pública, desestruturando a campanha de candidatos e resultando em novas estratégias.

A televisão ampliou, indiscutivelmente, o público que assiste às emissões políticas e declara um interesse por elas. Com a intensificação das exibições midiáticas, o meio político torna-se progressivamente, para o grande público, 
MOBILIZAÇÃO DA OPINIÃO PÚBLICA

um universo tão familiar quanto à do espetáculo.

O político tem necessidade da imprensa que, por sua vez, tem necessidade do político como fonte de informações ou, até mesmo, como personagem público que, por vezes, alimenta a crônica dos "escândalos" que podem fazer subir as tiragens. O jornalista só pode criar "o acontecimento" na medida em que o acontecimento que cria está em conformidade com a definição midiática do acontecimento (CHAMPAGNE, 1986, p. 260).

\section{MÍdIA, POLÍTICA E CIDAdANIA}

A mídia começa a assumir uma posição central na realidade contemporânea a partir do momento que se constitui como instituição mediadora dos discursos dos diferentes grupos e atores sociais. "A mídia moderna, supostamente tem criado novas condições para a política e a formação de identidade, e, certamente tem produzido novos espaços públicos". (EKECRANTZ, 2006, p. 94)

Sérgio Costa (2002) reforça o quanto os meios de comunicação são importantes para a constituição de um espaço público "politicamente influente" no cenário brasileiro. O autor defende que, a partir da década de 1980, os meios de comunicação se tornaram atores ativos do espaço público, contribuindo de forma mais efetiva para a construção da esfera pública.

"Para além da visibilidade e das ações estratégicas, torna-se importante entender os media como uma arena discursiva em que opiniões e argumentos são trocados e disputados". (MAIA, 2010, p.294)

Sendo assim, segundo Maia (2010), o ambiente midiático se torna um importante fórum para o debate cívico, onde associações cívicas lutam para articular publicamente seus objetivos e interesses, fundamental para que os representantes estabeleçam publicamente suas diferenças e busquem justificar, entre o conjunto de cidadãos, as políticas que pretendem impor uns aos outros.

O espaço de visibilidade criado pela mídia, embora marcado por profundas assimetrias na estruturação da comunicação dos atores sociais, contribui para a promoção de um diálogo público generalizado e para a criação de uma base reflexiva para a deliberação pública nas sociedades complexas.

Para Martín-Barbeiro as tecnologias não são neutras, pois hoje elas constituem grupos de condensação e interação de interesses econômicos e políticos 
com mediações sociais e conflitos simbólicos. "Mas, por isso mesmo, elas são constitutivas dos novos modos de construir opinião pública e das novas formas de cidadania, isto é, das novas condições em que se diz e se faz política". (2006, p.70)

Liszt Vieira (2001) acredita que a opinião pública não se constrói apenas do que passa na mídia. Primeiro é preciso entender conceitualmente a cidadania.

De acordo com Demo, a cidadania pode ser definida como a qualidade social de uma sociedade organizada sob a forma de direitos e deveres majoritariamente reconhecidos. Em relação aos direitos, são os ditos direitos humanos cuja conquista demorou milênios; já em relação aos deveres, são aqueles que aparecem, sobretudo com o compromisso comunitário de cooperação e corresponsabilidade.

Cidadania pressupõe o estado de direito, que parte, pelo menos na teoria, da igualdade de todos perante a lei e do reconhecimento de que a pessoa humana e a sociedade são detentores inalienáveis de direitos e deveres (DEMO, 1999, p. 67).

Partindo da ideia de Demo, Peruzzo afirma que cidadania é sustentada por três pilares: os direitos no campo da liberdade individual, que englobam liberdade, igualdade, locomoção e justiça; os direitos de participação no exercício do poder político, que juntam a participação política em todos os níveis como eleições, plebiscitos, participação em órgãos de representação tais como sindicatos, movimentos e associações; e os direitos sociais que conglomeram o direito e a igualdade de usufruto de um modo de vida digno, através do acesso ao patrimônio social ligado ao consumo, ao lazer, às condições e leis de trabaIho, à moradia, à educação, à saúde, à aposentadoria etc.

Peruzzo não está sozinha nesta definição,

cidadania é a síntese das conquistas dos direitos obtidos pelos homens, orientados por um principio básico: todos são iguais perante a lei, independentemente de raça, cor, sexo, religião e nacionalidade. $\mathrm{O}$ ser humano tem conhecido uma evolução dos direitos neste século: mulheres ganharam o direito de voto; leis racistas foram extirpadas; trabalhadores conseguiram proteção legal, etc. O conceito de cidadania hoje está também ligado à promoção de ações que garantam igualdade de oportunidades, assegurando a todos educação, saúde e nutrição. (DIMENTEIN, 2005, p.2) 


\subsection{Algumas contribuições na formação do cidadão}

Falar em formação da cidadania não é tarefa fácil. Principalmente pelo fato de que para a formação da cidadania dependem diferentes variáveis como família, escola, religião, crenças e costumes, entre outros.

A cidadania é um processo em construção, sendo assim, não está fechada e formatada em apenas um tipo de significado. Por isso, construir cidadania quer dizer também, construir novas relações e consciências. Pode-se perceber que a cidadania é algo que não se aprende com os livros, mas com a convivência, na vida social e pública. É no convívio do dia-a-dia que exercitamos a nossa cidadania, por meio das relações que estabelecemos com os outros, com a coisa pública e o próprio meio ambiente.

Assim, já que o processo para a cidadania é um processo de construção, esta prática está intimamente ligada à ideia de participação. Cidadania é processo construído por homens e mulheres, de forma ativa e responsável:

(...) a participação se torna não só um ato político, mas também educativo, na medida em que, por meio dela, se vão dando passos cada vez maiores. A ampliação da cidadania levará o homem e a mulher a serem, cada vez mais, sujeitos e não objetos da própria história (PERUZZO, 1998, p.287).

Por isso a importância do jornalista no processo político de determinada sociedade. Ser o agente externo capaz de provocar a participação. Paiva afirma que o agente externo deve ajudar a promover e potencializar a articulação comunitária, seja via instituições como prefeituras, órgãos municipais, organismos não governamentais; ou por meio da evocação de uma comunidade determinada (PAIVA, 1998, p. 164).

Dessa forma, as pessoas ao participarem e se perceberem como sujeitos, elas se tornam protagonistas da construção da cidadania e ficam mais próximas do processo de transformação social. Ao se sentirem inseridas no processo, as pessoas desenvolvem o seu conhecimento e mudam seu modo de ver e relacionar-se com a sociedade e com os próprios meios de comunicação.

Portanto, a cidadania é tarefa que não termina. A cidadania não é como um dever de casa, onde cada uma faz a sua parte, apresenta e pronto, acabou. Enquanto seres inacabados que somos, sempre estaremos buscando, descobrindo, criando e tomando consciência mais ampla dos direitos. Nunca poderemos 
chegar e entregar a tarefa pronta, pois novos desafios na vida social surgirão, demandando novas conquistas e, assim, mais cidadania. E nós, comunicadores temos de ser o canal para a formação da consciência crítica e ampliação da construção da cidadania.

\section{CONCLUSÃO}

A série de reportagens "Diários Secretos", investigada por jornalistas da Gazeta do Povo e veiculada pela RPCTV, veio à tona em pleno ano eleitoral, com isso, mobilizou a opinião pública, líderes de opinião e a sociedade em geral, ao divulgar dados da Assembléia Legislativa que estavam sendo encobertos por funcionários e políticos.

A cada veiculação das reportagens, grupos se manifestavam em frente à Assembléia para tentarem obter respostas e fazer justiça diante do que estavam recebendo de informação da mídia. Neste contexto, foi possível notar a influência da mídia na opinião pública, já que as informações eram passadas nos veículos de comunicação de massa e resultavam em manifestações e feedback. Para entender a atitude da população, foi necessário conhecer os conceitos de público, massa, multidão e outros citados no presente trabalho, para enfim compreender quem é a opinião pública e qual o papel dos institutos de sondagens.

Ao se relacionar o tema da opinião pública com o caso em questão, podese perceber que a visão de Landowski (1992) faz todo sentido, já que para o autor, é fundamental para a formação da opinião pública a presença do coro ou corifeu, o intermediário entre os atores políticos e a população. O chefe do coro são os porta-vozes, ou seja, os jornalistas que denunciam os abusos na Assembléia Legislativa.

Na visão de Landowski, a opinião pública é vista como construção discursiva, um artefato de linguagem que se inscreve em estratégias que se prendem à manipulação das multidões, já que a emergência da opinião pública é aplicada na mídia massiva, sendo a massa a expectadora da cena pública. Sendo assim, a sondagem é um componente fundamental para a formação da opinião pública, para se conhecer o comportamento desta plateia.

A opinião pública dos institutos de sondagem é simplesmente a agregação de opiniões privadas que se tornam públicas. Não é uma opinião que se exprime em público, quer seja por petições, tribuna livre 
na imprensa, declaração na televisão, carta ao leitor (...). Tornar ou não pública a sua opinião é um ato político (CHAMPAGNE, 1986, p.113)

Landowski (1992, p. 29) vai além da citação acima de Champagne quando afirma que "a pesquisa quantitativa tem como razão de ser a ideia de que a opinião representa um quantum de poder objetivamente mensurável”, o que só o procedimento intuitivo dos porta-vozes pode revelar é o segredo insondável do querer que conduz essa força.

Contrariando o pensamento de Habermas, que diz que hoje o jornalismo é espetáculo e não reflexão, já que as notícias são mercadorias, a RPCTV e a Gazeta do Povo divulgaram os abusos e a corrupção na AL, podendo dizer que a postura dos veículos acima era exatamente ir contra o jogo político que há na sociedade.

Para Habermas, a esfera pública aparece como instância mediadora entre o estado e a esfera privada, sendo que a esfera pública é o Estado e esfera privada é o mercado (homens de negócios). Também é na esfera pública que há o Estado administrativo e organizado, onde se predomina a racionalização da dominação e o controle da opinião pública.

Hoje, segundo ele, vive-se em democracias de massa sob condições da propaganda política (mercado) ao invés do discurso racional intersubjetivo entre iguais. A organização e a manipulação da massa são calculadamente sob a lógica do poder econômico.

Pela observação das matérias produzidas e divulgadas pelos veículos em questão, se pode notar que com as denúncias dos abusos da Assembleia Legislativa, os jornalistas buscavam a dimensão comunicativa preconizada por Habermas, já que com isso esperavam avançar para um pensamento mais aberto, possibilitando abrir para oportunidades e um entendimento mais abrangente e não restritivo.

Segundo Habermas, no agir comunicativo o homem é um ser reflexivo, participativo e argumentativo, com valor comunicacional aberto e autônomo, dependendo do uso da linguagem dirigida de forma ao entendimento, em que as decisões são tomadas cooperativamente e compartilhadas. Para ter certeza de que houve, de fato, essas características no público atingido pelas denúncias seria necessária uma análise mais aprofundada, o que não era o propósito do presente texto, e sim apenas traçar as características da opinião pública no processo de denúncias dos veículos já citados.

Por isso, pode-se perceber, que a RPCTV, ao mostrar/divulgar/incentivar os Diários Secretos para a sociedade, ajuda na conscientização do sujeito, que, 
por conseguinte, reforça sugerindo uma participação política dos indivíduos da sociedade, auxiliando no processo de tomada de consciência para o processo de transformação da sociedade paranaense.

\section{REFERÊNCIAS}

CHAMPAGNE, Patrick. Formar opinião: o novo jogo político. Petrópolis, RJ: Vozes, 1996

COHN, Gabriel. Comunicação e indústria cultural: leituras de análise dos meios de comunicação na sociedade contemporânea e das manifestações da opinião pública, propaganda e cultura de massa nessa sociedade. São Paulo: Editora Nacional, 1978

COSTA, Sérgio. As cores de Ercília. Belo Horizonte: UFMG, 2002.

DEMO, Pedro. Participação é conquista - Noções de política social e participação. São Paulo, SP: Cortez, 1999.

DIMENSTEIN, Gilberto. $O$ cidadão de papel: a infância, a adolescência e os direitos humanos no Brasil. 19.ed. São Paulo: Ática, 2001

EKENCRANTZ, Jan. In: MAIA, R.; CASTRO, M. C. (orgs.) Mídia, esfera pública e identidades coletivas. Belo Horizonte: UFMG, 2006).

KATZ, Daniel. Attitude formation and public opinion, annals of the Americas Academiy of Political and Social Sciences, n 367, setembro de 1966. p. 150-62, Tradução de Gabriel Cohn LANDOWSKI, Eric. A sociedade refletida: ensaios de sociossemiótica. São Paulo: EDUC/Pontes, 1992

MAIA, Rousiley. In: MIGUEL, L. F.; BIROLI, F. (orgs) Mídia, representação e democracia. São Paulo: Hucitec, 2010.

MARTÍN-BARBERO, Jesús. In: MORAES, Denis de (org.). Sociedade midiatizada. Rio de Janeiro: Mauad, 2006.

PAIVA, Raquel. 0 espírito comum: comunidade, mídia e globalismo. Petrópolis, RJ: Vozes, 1998.

PERUZZO, Cecília M. Kroling. Comunicação nos movimentos populares. Petrópolis, RJ: Vozes, 1998.

PERUZZO, Cecília M. Kroling. Comunicação comunitária e educação para cidadania.

Disponível em: <http://www.usp.br/nce/aeducomunicacao/saibamais/textos/>. Acesso em: 15 jun. 2012.

TARDE, Gabriel. A opinião e as massas. São Paulo: Martins Fontes, 1992

TESSER, Gelson João. A teoria crítica de Habermas. Power Point, 2011

THIOLLENT, Michel. Crítica metodológica, investigação social e enquete operária. São Paulo: Editora Polis, 1987 
MOBILIZAÇÃO DA OPINIÃO PÚBLICA

VIÁ, Sarah Shucid da. Opinião pública: técnicas de formação e problemas de controle. São Paulo: Loyola, 1983

VIEIRA, Liszt. Os argonautas da cidadania. Rio de Janeiro: Record, 2001.

WOLF, Mauro. Teorias da comunicação. Lisboa: Presença, 2002

Site consultado. Disponível em:<http://www.gazetadopovo.com.br/vidapublica/diariossecretos/conteudo.phtml?id=996090>. Acesso em: 21 jul. 2012

RECEBIDO EM: 15/10/12

ACEITO PARA PUBLICAÇÃO: 31/10/12

\section{Anne Carolina Festucci}

Mestranda em Comunicação da UFPR. Graduada em Comunicação Social - Habilitação Jornalismo pela Universidade Estadual de Londrina (UEL) e especialista em Comunicação Popular e Comunitária também pela UEL. Analista de Comunicação no Sistema Federação das Indústrias do Estado do Paraná (FIEP).

\section{Patricia Guilhem de Salles Carvalho}

Mestranda em Comunicação da UFPR Graduada em Comunicação Social - Habilitação Publicidade e Propaganda pela PUCPR e em Administração de Empresas pela Faculdades Positivo. Especialista em Gestão Pública pela Faculdade de Tecnologia. Produtora cultural na UFPR.

\section{Paula Maia Wunder Andreola}

Mestranda em Comunicação da UFPR. Graduada em Comunicação Social - Habilitação Relações Públicas pela PUCPR. Especialista em Comunicação Estratégica e Negócios pela PUCPR. Professora no curso de Comunicação na PUCPR. 